\title{
A TERRITORIALIZAÇÃO DO MONOPÓLIO CAPITALISTA CANAVIEIRO EM GOIÁS, BRASIL
}

\author{
Fernando Uhlmann Soares ${ }^{1}$ \\ Ricardo Junior de Assis Fernandes Gonçalves ${ }^{2}$ \\ Valdir Specian ${ }^{3}$
}

Resumo: Objetivou-se com a presente pesquisa analisar a expansão canavieira em Goiás, Brasil. Apresenta-se, assim, a recente disputa entre os processos de monopolização graneleira do território e o de territorialização do capitalismo monopolista canavieiro nos territórios do Cerrado goiano. A metodologia baseou-se no levantamento de dados e informações qualitativas e quantitativas, foram elaborados mapas sobre o avanço das áreas de cultivo canavieiro, bem como instalação de usinas e produção sucroenergética. Os resultados revelam a monopolização do território no processo produtivo graneleiro vigente e a disputa com a territorialização do monopólio canavieiro.

Palavras-chave: Território; Cerrado; Cana-de-açúcar; Setor Sucroenergético.

\section{THE TERRITORIALIZATION OF THE CAPITALIST SUGAR CANE MONOPOLY IN GOIÁS, BRAZIL}

\begin{abstract}
The objective of this research was to analyze the sugarcane expansion in Goiás, Brazil. Thus, the recent dispute between the processes of monopolization of the territory and the territorialisation of the monopoly of sugarcane capitalism in the territories of the Cerrado of Goiás is presented. The methodology was based on the collection of data and qualitative and quantitative information, maps were elaborated on the advance of the areas of sugarcane cultivation, as well as installation of plants and sugar-energy production. The results reveal the monopolization of the territory in the current bulk production process and the dispute with the territorialization of the sugarcane monopoly.
\end{abstract}

Keywords: Territory; Cerrado; Sugarcane; Sugar-energy Sector.

\footnotetext{
${ }^{1}$ Professor do Instituto Federal Goiano - Campus Rio Verde. Doutorando no Programa de Pós-Graduação Stricto Sensu em Geografia da Universidade Federal de Goiás (UFG) - Regional Jataí. fernando.soares@ifgoiano.edu.br

${ }^{2}$ Professor na Graduação e Pós-Graduação em Geografia da Universidade Estadual de Goiás (UEG). Pós-Doutorando no Programa de Pós-Graduação em Geografia da Universidade Federal de Juiz de Fora (UFJF). ricardo.goncalves@ueg.br

${ }^{3}$ Professor da Universidade Estadual de Goiás (UEG). Doutorando no Programa de Pós-Graduação Stricto Sensu em Geografia da Universidade Federal de Goiás (UFG) - Regional Jataí. vspecian@ gmail.com.

Estudos Geográficos, Rio Claro, 17(1): 93-105, jan./jun. 2019 (ISSN 1678-698X) http://www.periodicos.rc.biblioteca.unesp.br/index.php/estgeo
} 
A territorialização do monopólio capitalista...

\section{INTRODUÇÃO}

As implicações territoriais da expansão do capitalismo extrativo (PETRAS, 2014) no Cerrado goiano no decorrer do século XX revelam um território internacionalizado e controlado por grandes corporações produtoras de commodities. Territorializa-se um modelo de explotação sistemática da terra, da água e do trabalho. Consequentemente, os setores produtivos de grãos, cana-deaçúcar e minérios tornaram-se dependentes do uso intensivo das "dádivas gratuitas da natureza" (HARVEY, 2018) e da inserção subordinada na Divisão Internacional do Trabalho (DIT).

As monoculturas graneleira e canavieira em grande escala são expressões concretas do uso corporativo do território cerradeiro goiano. Isso faz com que o Bioma-Território Cerrado (CHAVEIRO, 2010) seja sistematicamente transformado em objeto de exploração mercantil integrado às redes globais de produção. Esse processo palmilha a estratégia geopolítica de transformação do Cerrado goiano em fronteira do capital extrativo internacional.

A atual fase de territorialização da monocultura de cana-de-açúcar no Cerrado goiano engloba o paradigma da hipermobilidade constituído pelos fluxos de mercadorias, capitais e trabalhadores. As peças fundamentais desse processo são a hegemonia da indústria automobilística e a exportação de açúcar que determinam o sentido geopolítico do Cerrado goiano a partir da produção de etanol e de açúcar. Desse modo, convém interpretar as disputas e os conflitos territoriais advindos dessa estratégia geopolítica.

Doravante, a centralidade desta pesquisa está em compreender a territorialização do capitalismo monopolista canavieiro em Goiás. Para isso, demonstra-se a expansão do setor canavieiro no Cerrado goiano e as escalas de apropriação e controle dos territórios. A metodologia baseia-se no levantamento de dados e informações qualitativas e quantitativas. Assim, foram elaborados mapas sobre o avanço das áreas de cultivo canavieiro, bem como instalação de usinas e produção sucroenergética.

Em suma, os resultados sublinham a apropriação dos territórios para a produção de cana-de-açúcar nos últimos anos e revelam as transformações territoriais e os mecanismos de controle da terra no Cerrado. Como efeito, a territorialização do setor sucroenergético em Goiás, no decorrer da primeira década do século XXI, contribui para a apreensão do movimento expansionista do capital extrativo e a inserção de novos territórios e trabalhadores na urdidura da exploração capitalista monopolista e mundializada.

\section{AS NOVAS FRONTEIRAS DO CAPITAL EXTRATIVO E A EXPANSÃO DA MONOCULTURA DA CANA-DE-AÇÚCAR}

Segundo Oliveira (2016), a agricultura no capitalismo monopolista mundializado estrutura-se sobre uma tríade representada pela produção de commodities, formação das empresas monopolistas mundiais e pelas bolsas de mercadorias e de futuro. Um dos efeitos disso é a transformação radical da produção do campo em produção de commodities que circulam nas redes do mercado global. Sendo assim, compreende-se que a expansão da monocultura de cana-de-açúcar em Goiás é uma expressão do processo de territorialização dos monopólios no estado.

Estudos Geográficos, Rio Claro, 17(1): 93-105, jan./jun. 2019 (ISSN 1678-698X) http://www.periodicos.rc.biblioteca.unesp.br/index.php/estgeo 
A introdução e o avanço da monocultura da cana no Brasil e particularmente nos territórios do Cerrado permitem refletir sobre o avanço do capital extrativo no contexto de mundialização do capital. Sendo assim, o avanço da canavicultura, a integração geopolítica, as implicações ambientais, os efeitos nos territórios das populações camponesas e tradicionais colaboram com a interpretação geográfica e crítica desse Bioma-Território (CHAVEIRO, 2010) em Goiás.

Desse modo, a sequência de mapas a seguir, Figura 1, ilustram a espacialização e evolução da área de plantio de cana-de-açúcar no Brasil conforme dados do Instituto Brasileiro de Geografia e Estatísticas (IBGE) para os anos de 2000, 2005, 2010 e 2015.

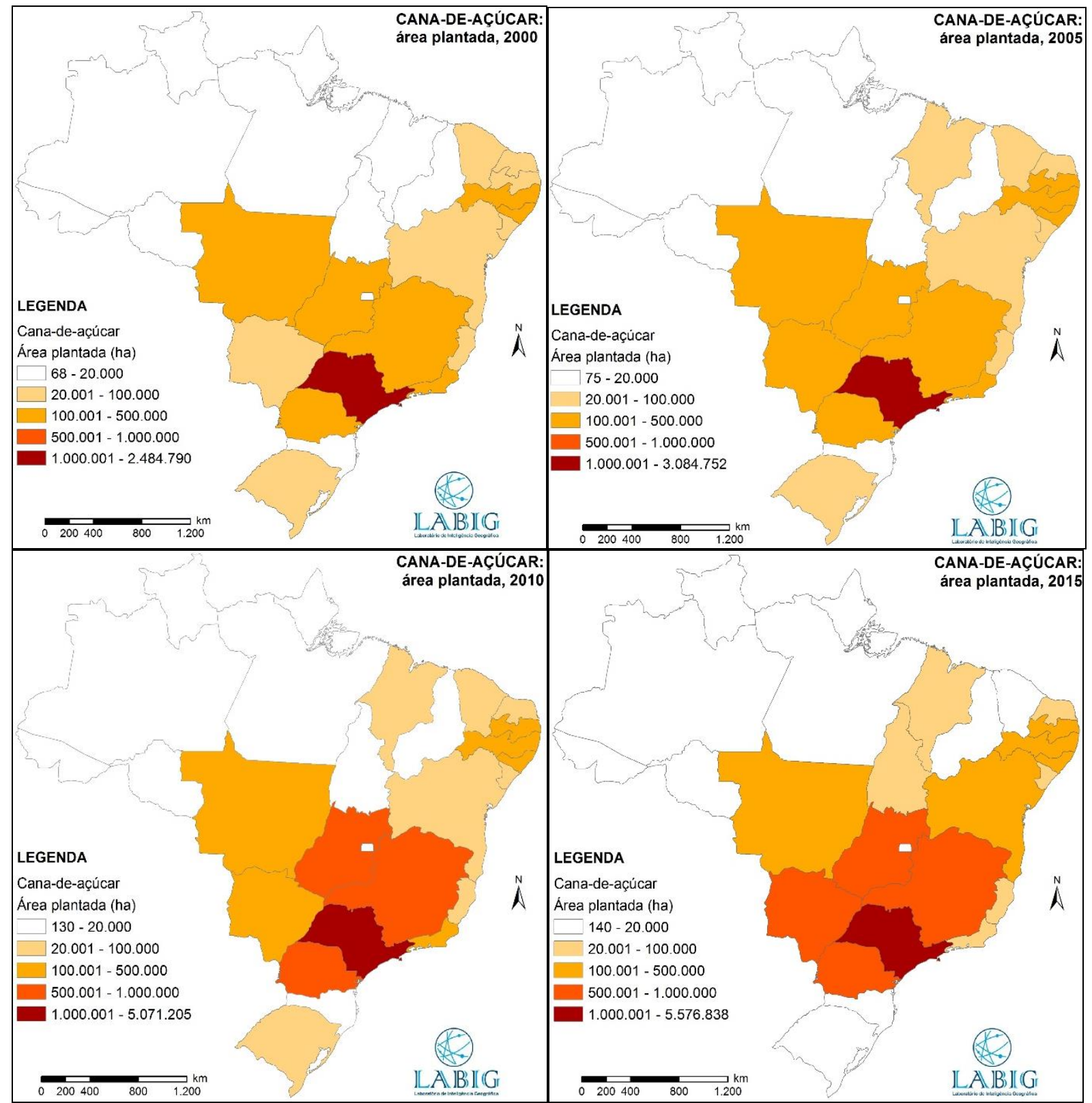

Mapa 1 - Evolução da área plantada com cana-de-açúcar no Brasil, 2000-2015.

Fonte: IBGE, 2017.

Elaboração: Autores.

Estudos Geográficos, Rio Claro, 17(1): 93-105, jan./jun. 2019 (ISSN 1678-698X) http://www.periodicos.rc.biblioteca.unesp.br/index.php/estgeo 
Em relação ao Brasil, a canavicultura continua avançando por novas áreas dos estados brasileiros, caracterizando a expansão das novas fronteiras do capital extrativo no país. Avançou notoriamente por Minas Gerais, Goiás, Santa Catarina e, mais recentemente, sobre o Mato Grosso do Sul. Enquanto as áreas se expandem sobre todo o território nacional, apenas os estados do Ceará e do Rio Grande do Sul apresentaram diminuição nas áreas de plantio.

No geral, nota-se que as áreas mínima e máxima plantadas tiveram seus hectares dobrados passando, respectivamente, de 68 hectares para 140 e de aproximados 2.5 milhões para mais de 5 milhões no período dos 15 anos analisados.

Os mapas indicam a ampliação da área plantada no Brasil ao longo dos primeiros 15 anos do século XXI e que a mesma chegou com intensidade às áreas de Cerrado no Centro-Oeste do país. Assim, são notórios os avanços da produção canavieira no território brasileiro e, sobretudo, no que concerne aos estados do Centro-Oeste brasileiro e suas áreas de Cerrado e de outras commodities.

Com ênfase em Goiás, desde o início da década de 2000 seu território passou a ser uma das principais fronteiras de expansão do setor sucroenergético. Por conseguinte, a área de plantio cresceu significativamente, passando de quase 140 mil hectares no ano de 2000 para mais de 900 mil hectares até 2015. Isso representou um aumento de $85 \%$ da área cultiva no território goiano em 15 anos.

Antes mesmo dessa recente expansão, em 1975 o governo de Ernesto Geisel acenou com a implantação do Programa Nacional do Álcool (Proálcool). De acordo com Oliveira (2004), este Programa foi o responsável pelo financiamento da atividade canavieira com incentivos fiscais ou empréstimos bancários com juros baixos para produção de cana, o que visava o abastecimento do mercado nacional com o álcool combustível.

Essa situação pode ser compreendida quando Cruz (2012) afirma que o Proálcool reorganizou a estrutura socioespacial brasileira ao concentrar e centralizar o capital das usinas na região Centro-Sul ao mesmo tempo em que exigiu a abertura de novas fronteiras agrícolas e especializou porções do território para produzir álcool combustível, fortalecendo a hegemonia do modal rodoviário no país.

As implicações territoriais desse processo compreenderam a integração de novos territórios às dinâmicas de expansão do capital monopolista canavieiro. Assim, para Santos (2012), a expansão do cultivo de cana em Goiás ocorreu associada à um discurso de recuperação de áreas de pastagens degradadas. Alguns municípios do Sudoeste de Goiás como Quirinópolis, Rio Verde, Jataí e Mineiros, que são os municípios de maior concentração de produção de cana e de outras monoculturas, vêm experimentando uma reorganização dos seus territórios.

Santos (2012) ressalta ainda que a produção canavieira em 2000 no Sudoeste de Goiás apresentava irrelevante. Com a instalação de usinas sucroalcooleiras nessa região, entre 2005 e 2009 houve um crescimento dessa produção que diferentemente do discurso utilizado foi se estabelecer nas áreas de produção de soja, milho e sorgo, que exigiam menos investimentos e são de fácil mecanização.

O mapa a seguir, Figura 2, apresenta a espacialização da produção canavieira do Brasil de 2015 na qual o estado de Goiás aparece como um dos principais destaques.

Logo, o território goiano tornou-se o segundo maior produtor com mais de 70 milhões de toneladas produzidas, ficando apenas atrás do tradicional estado de São Paulo, com tem quase 425 milhões.

Estudos Geográficos, Rio Claro, 17(1): 93-105, jan./jun. 2019 (ISSN 1678-698X) http://www.periodicos.rc.biblioteca.unesp.br/index.php/estgeo 
Apesar da grande diferença numérica entre a produção de cana-de-açúcar nos estados brasileiros, os dados refletem que o modelo de monopolização canavieira do território vem ganhando espaço além de São Paulo. Os territórios de Goiás, Minas Gerais e Paraná são confirmados como prioritários no avanço dos investimentos canavieiros se levados em consideração os dados de 2000 a 2015.

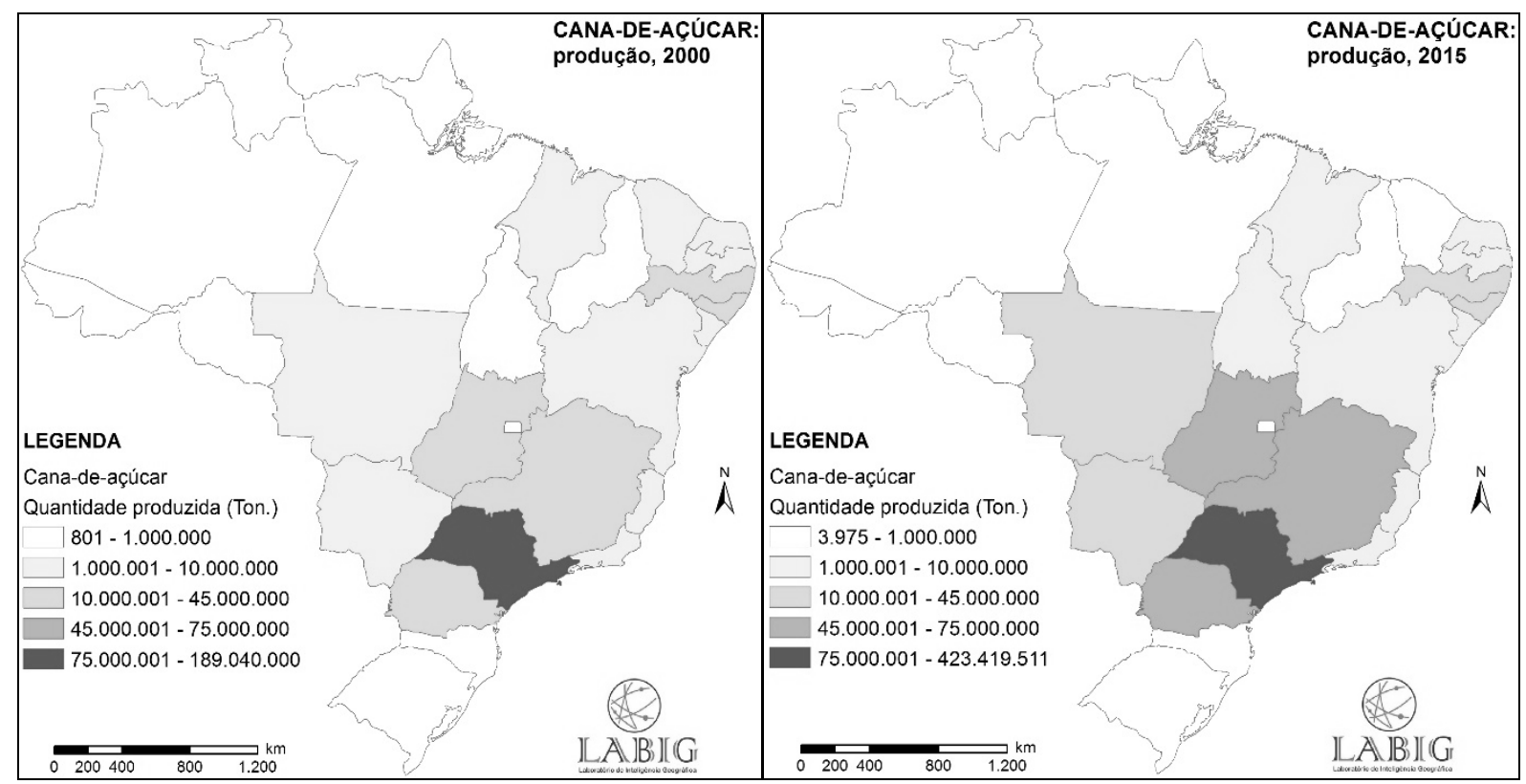

Mapa 2 - Evolução da área plantada com cana-de-açúcar no Brasil entre 2000 e 2015. Fonte: IBGE, 2017.

Elaboração: Autores.

Parte do avanço canavieiro sobre as áreas de Cerrado pode ser justificado a partir do lançamento do Plano Nacional de Agroenergia 2006-2011 pelo Ministério da Agricultura, Pecuária e Abastecimento (BRASIL 2006). Tal plano reuniu ações estratégicas para reduzir o uso de combustíveis fósseis, ao mesmo tempo em que ampliou a produção e consumo de biocombustíveis.

Entre suas metas, o zoneamento agroecológico de espécies importantes para a agroenergia, como a cana, segue orientando investimentos públicos e privados em áreas tradicionais e de expansão de fronteiras agrícolas. Ainda, o melhoramento genético pelas vias tradicional e biotecnológica aprimora a produtividade sem significativa expansão das terras cultivadas (SOARES, 2008) apesar da constante evolução na captação de terras para plantio via compra ou arrendamento.

O que se observa é que vários estados brasileiros e, principalmente Goiás, aumentaram seus plantios de cana em decorrência das melhorias na produção, se apropriaram de terras de usos diversos e instalaram usinas do setor sucroenergético.

No entanto, diferentemente do que orientava o Plano de Agroenergia, este cenário realiza-se a partir da ampliação da área desmatada ou da substituição daquela utilizada na produção de grãos, além de trazer uma série de efeitos socioambientais, como a exaustão dos solos e das águas, precarização e precariedade das relações de trabalho e conflitos territoriais com populações camponesas e tradicionais.

Estudos Geográficos, Rio Claro, 17(1): 93-105, jan./jun. 2019 (ISSN 1678-698X) http://www.periodicos.rc.biblioteca.unesp.br/index.php/estgeo 


\section{A TERRITORIALIZAÇÃO DO MONOPÓLIO CAPITALISTA CANAVIEIRO EM GOIÁS}

Segundo o estudo de Silva (2012), a expansão da produção canavieira goiana está baseada no atendimento das crescentes demandas nacional e internacional por etanol. Essa situação faz com que a quantidade de unidades industriais instaladas venha crescendo e projeta-se um total de mais de 80 unidades para o ano de 2018. Isso revela, por consequência, a territorialização do capitalismo monopolista canavieiro nos territórios do Cerrado em Goiás.

A partir dos dados disponíveis do Sindicato da Indústria de Fabricação de Etanol do Estado de Goiás (SIFAEG) foram especializados, Figura 3, a distribuição e o número de indústrias do setor sucroalcooleiro em 2003 e 2016.

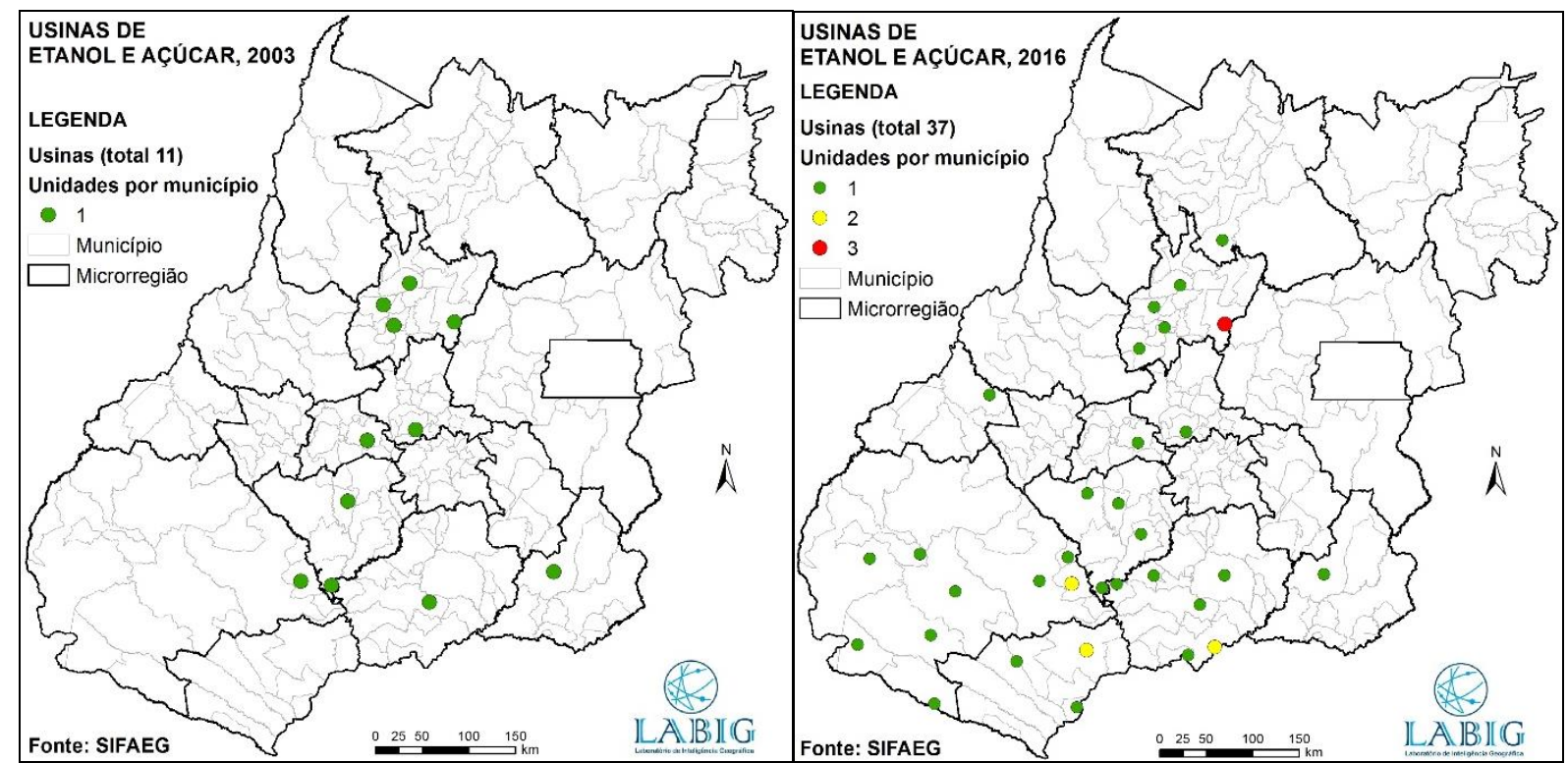

Mapa 3 - Evolução do número de usinas instaladas em Goiás nos anos 2003 e 2016. Fonte: SIFAEG.

Elaboração: Autores.

Em 2003, a principal área de instalação das usinas sucroenergéticas era a microrregião de Ceres que possuía quatro unidades. Os demais municípios identificados tinham apenas uma usina cadastrada no SIFAEG. Nota-se que no mesmo ano existia apenas uma empresa instalada no Sudoeste de Goiás apesar da grande dimensão territorial da microrregião, do relevo plano e dos solos ricos que favorecem a mecanização e o estabelecimento da grande propriedade monocultora canavieira quando comparada às demais regiões.

Já no ano de 2016, apesar da microrregião de Ceres ter praticamente duplicado o número de usinas cadastradas, passando a ter sete unidades, foi a microrregião do Sudoeste de Goiás que despontou em números de usinas com um total de 10. Esse avanço para a porção sul do estado, demonstra a predileção e o avanço do setor nesta microrregião, principalmente após verificadas as condições de atendimento aos interesses da Revolução Verde nos anos 1970/80.

No mesmo sentido, a microrregião do Meia Ponte que tinha em 2003 apenas uma usina, passou a ter sete unidades instaladas em 2016. A microrregião do Vale do Rio dos Bois de duas usinas passou a contar com quatro em 2016, e a

Estudos Geográficos, Rio Claro, 17(1): 93-105, jan./jun. 2019 (ISSN 1678-698X) http://www.periodicos.rc.biblioteca.unesp.br/index.php/estgeo 
microrregião de Quirinópolis, que não tinha usinas em 2003, passa a ter quatro unidades segundo dados do SIFAEG (2017).

Para Rodrigues (2013), a busca por uma maior rentabilidade e/ou produtividade impulsiona o uso de novas tecnologias e a intensificação no uso do solo caracterizando essa expansão da fronteira da produção canavieira em Goiás.

Em municípios do Sudoeste de Goiás, como Jataí e Rio Verde, no quais ocorre a monopolização do território a partir do processo produtivo graneleiro da soja, sorgo e milho, se vislumbra, atualmente, uma outra situação com a territorialização do monopólio canavieiro. Se no primeiro caso, o capitalista industriário e o proprietário de terras eram pessoas distintas, com a canavicultura estas classes sociais se unificam e tendem a se transformar na mesma pessoa jurídica. Conforme Oliveira (2015) o estudo da agricultura brasileira deve ser feito no bojo da compreensão dos processos de desenvolvimento do modo capitalista de produção.

Assim, tratando-se de um momento de reestruturação do modelo produtivo nos territórios do Cerrado em Goiás e para um melhor entendimento dessa situação, foram identificadas, Quadro 1, as indústrias de etanol cadastradas no SIFAEG no intervalo entre 2003 e 2016.

\section{Quadro 1 - Indústrias cadastradas no Sindicato da Indústria de Fabricação de Etanol do Estado de Goiás nos anos de 2003, 2004, 2005, 2013 e 2016.}

\begin{tabular}{|c|c|c|c|c|c|c|c|c|}
\hline & USINA & ENDEREÇO & MUNICÍPIO & 2003 & 2004 & 2005 & 2013 & 2016 \\
\hline 1 & $\begin{array}{l}\text { ANICUNS S/A } \\
\text { ÁLCOOL E } \\
\text { DERIVADOS }\end{array}$ & $\begin{array}{c}\text { Rod. } \\
\text { Anicuns/Americ } \\
\text { ano do Brasil, } \\
\text { km } 06\end{array}$ & Anicuns & X & X & $x$ & $x$ & $x$ \\
\hline 2 & $\begin{array}{c}\text { BOM SUCESSO } \\
\text { AGROINDÚSTRIA } \\
\text { LTDA }\end{array}$ & $\begin{array}{l}\text { Rod. GO 210, } \\
\text { km 335,1 }\end{array}$ & Goiatuba & & & & $x$ & \\
\hline 3 & $\begin{array}{c}\text { BRENCO - USINA } \\
\text { MORRO } \\
\text { VERMELHO - } \\
\text { ODEBRECHT } \\
\text { AGROINDUSTRIAL }\end{array}$ & $\begin{array}{l}\text { Rod. GO 341, } \\
\text { km 68, Faz. } \\
\text { Morro Vermelho }\end{array}$ & Mineiros & & & & $x$ & $x$ \\
\hline 4 & $\begin{array}{l}\text { BRENCO - USINA } \\
\text { PEROLÂNDIA- } \\
\text { ODEBRECHT } \\
\text { AGROINDUSTRIAL }\end{array}$ & $\begin{array}{c}\text { Rod. BR 364, } \\
\text { km 256, s/n }\end{array}$ & Perolândia & & & & $X$ & X \\
\hline 5 & $\begin{array}{l}\text { BP BIOENERGIA } \\
\text { ITUMBIARA S/A }\end{array}$ & $\begin{array}{l}\text { Estr. Mun. } \\
\text { Itumbiara/ } \\
\text { Cachoeira } \\
\text { Dourada, km 18, } \\
\text { Faz. Jandaia, } \\
\text { Gleba B }\end{array}$ & Itumbiara & & & & & X \\
\hline 6 & $\begin{array}{l}\text { BP BIOENERGIA } \\
\text { TROPICAL S/A }\end{array}$ & $\begin{array}{c}\text { Rodovia } \\
\text { TakayukiMaeda } \\
\text { (GO 410), Km } \\
51\end{array}$ & Edéia & & & & & $x$ \\
\hline 7 & $\begin{array}{l}\text { CAÇU COMÉRCIO } \\
\text { E IND. DE AÇÚCAR } \\
\text { E ÁLCOOL LTDA. }\end{array}$ & $\begin{array}{c}\text { Rod. Mun. } \\
\text { Vicentinópolis/ } \\
\text { Porteirão, km } 10\end{array}$ & $\begin{array}{l}\text { Vicentinó- } \\
\text { polis }\end{array}$ & & & & $x$ & $x$ \\
\hline 8 & $\begin{array}{l}\text { CAMBUÍ ACUÚCAR E } \\
\text { ÁLCOOL LTDA }\end{array}$ & $\begin{array}{c}\text { Rod. BR 452, } \\
\text { km 33, Faz. San } \\
\text { Carlos }\end{array}$ & $\begin{array}{l}\text { Santa } \\
\text { Helena de } \\
\text { Goiás }\end{array}$ & & & & $X$ & $x$ \\
\hline
\end{tabular}

http://www.periodicos.rc.biblioteca.unesp.br/index.php/estgeo 
A territorialização do monopólio capitalista...

\begin{tabular}{|c|c|c|c|c|c|c|c|c|}
\hline 9 & $\begin{array}{l}\text { CEM - CENTRAL } \\
\text { ENERGÉTICA } \\
\text { MORRINHOS S/A }\end{array}$ & $\begin{array}{l}\text { Rod. BR 153, } \\
\text { km 646, Faz. } \\
\text { Samambaia }\end{array}$ & Morrinhos & & & & $\mathrm{X}$ & $\mathrm{x}$ \\
\hline 10 & $\begin{array}{c}\text { CENTRAL } \\
\text { ITUMBIARA DE } \\
\text { BIONERGIA E } \\
\text { ALIMENTOS S/A }\end{array}$ & $\begin{array}{l}\text { Estr. Mun. } \\
\text { Itumbiara/Cacho } \\
\text { eira Dourada, } \\
\text { km 18, Faz. } \\
\text { Jandaia, Gl. B }\end{array}$ & Itumbiara & & & & $\mathrm{X}$ & \\
\hline 11 & $\begin{array}{l}\text { CENTROÁLCOOL } \\
\text { S/A - CENASA }\end{array}$ & $\begin{array}{c}\text { Rod. } \\
\text { Inhumas/Anápol } \\
\text { is, } \mathrm{km} 03\end{array}$ & Inhumas & $x$ & $x$ & $x$ & $\mathrm{X}$ & $x$ \\
\hline 12 & $\begin{array}{l}\text { CERRADINHO } \\
\text { BIOENERGIA S/A }\end{array}$ & $\begin{array}{l}\text { Rod. GO 050, } \\
\text { km } 11+950 \mathrm{~m}, \\
\text { Faz. Âncora }\end{array}$ & $\begin{array}{l}\text { Chapadão } \\
\text { do Céu }\end{array}$ & & & & $\mathrm{X}$ & $\mathrm{x}$ \\
\hline 13 & $\begin{array}{c}\text { COOPERATIVA } \\
\text { AGROINDUSTRIAL } \\
\text { DE RUBIATABA } \\
\text { LTDA }\end{array}$ & $\begin{array}{c}\text { Rodovia GO } \\
434, \mathrm{~km} 24\end{array}$ & Rubiataba & $x$ & $x$ & $x$ & $\mathrm{X}$ & $\mathrm{x}$ \\
\hline 14 & $\begin{array}{c}\text { COSAN } \\
\text { CENTROESTE S/A } \\
\text { AÇÚCAR E } \\
\text { ÁLCOOL }\end{array}$ & $\begin{array}{l}\text { Rod. GO 406, } \\
\text { km 25, } 6 \mathrm{~km} \text { à } \\
\text { dir., Faz. Santo } \\
\text { Antônio do Rio } \\
\text { Doce }\end{array}$ & Jataí & & & & $x$ & \\
\hline 15 & $\begin{array}{c}\text { CRV INDUSTRIAL } \\
\text { LTDA }\end{array}$ & $\begin{array}{c}\text { Rod. Carmo do } \\
\text { Rio } \\
\text { Verde/Rubiatab } \\
\text { a, km 2,5 } \\
\end{array}$ & $\begin{array}{l}\text { Carmo do } \\
\text { Rio Verde }\end{array}$ & $x$ & $x$ & $x$ & $x$ & $x$ \\
\hline 16 & $\begin{array}{c}\text { DENUSA - } \\
\text { DESTILARIA NOVA } \\
\text { UNIÃO S/A }\end{array}$ & $\begin{array}{l}\text { Rod. BR 060, } \\
\text { margem esq., } \\
\text { km } 274\end{array}$ & Jandáia & $x$ & $x$ & $x$ & $x$ & $x$ \\
\hline 17 & $\begin{array}{c}\text { EBER BIO- } \\
\text { ENERGIA E } \\
\text { AGRICULTURA } \\
\text { LTDA } \\
\end{array}$ & $\begin{array}{l}\text { Rod. GO 070, } \\
\text { km 030, 3km à } \\
\text { esq. }\end{array}$ & $\begin{array}{l}\text { Montes } \\
\text { Claros de } \\
\text { Goiás }\end{array}$ & & & & & $\mathrm{x}$ \\
\hline 18 & $\begin{array}{c}\text { ENERGÉTICA SÃO } \\
\text { SIMÃO S/A }\end{array}$ & $\begin{array}{c}\text { Rod. GO 164, } \\
\text { km 02, Faz. } \\
\text { Pateiro }\end{array}$ & São Simão & & & & $x$ & $\mathrm{X}$ \\
\hline 19 & $\begin{array}{c}\text { ENERGÉTICA } \\
\text { SERRANÓPOLIS } \\
\text { LTDA }\end{array}$ & $\begin{array}{l}\text { Rod. GO 184, } \\
\text { km 65, Faz. } \\
\text { Bonito }\end{array}$ & Serranópolis & & & $x$ & $x$ & $\mathrm{x}$ \\
\hline 20 & $\begin{array}{c}\text { FLORESTA S/A } \\
\text { AÇÚCAR E } \\
\text { ÁLCOOL }\end{array}$ & $\begin{array}{c}\text { Rod. BR 060, } \\
\text { km 351, Faz. } \\
\text { Floresta }\end{array}$ & $\begin{array}{c}\text { Santo } \\
\text { Antônio da } \\
\text { Barra }\end{array}$ & & & & $\mathrm{X}$ & $\mathrm{x}$ \\
\hline 21 & $\begin{array}{c}\text { GOIASA - } \\
\text { GOIATUBA } \\
\text { ÁLCOOL LTDA }\end{array}$ & $\begin{array}{l}\text { Rod. GO 040, } \\
\text { km 194, } 7 \mathrm{~km} \text { à } \\
\text { dir. }\end{array}$ & Goiatuba & $x$ & $x$ & $x$ & $x$ & $\mathrm{x}$ \\
\hline 22 & $\begin{array}{c}\text { JALLES MACHADO } \\
\text { S/A }\end{array}$ & $\begin{array}{c}\text { Rod. GO 080, } \\
\text { km 71.5, Faz. } \\
\text { São Pedro }\end{array}$ & Goianésia & $x$ & $x$ & $x$ & $x$ & $\mathrm{x}$ \\
\hline 23 & $\begin{array}{c}\text { JALLES MACHADO } \\
\text { S/A - UNIDADE } \\
\text { OTÁVIO LAGE }\end{array}$ & $\begin{array}{c}\text { Rod. GO 338, } \\
\text { km 33, 3km à } \\
\text { esq. }\end{array}$ & Goianésia & & & & $X$ & $\mathrm{x}$ \\
\hline 24 & $\begin{array}{c}\text { LASA - LAGO AZUL } \\
\text { S/A }\end{array}$ & $\begin{array}{c}\text { BR 050, km } \\
\text { 154, Faz. Lago } \\
\text { Azul } \\
\end{array}$ & Ipameri & $x$ & $x$ & $x$ & $X$ & $\mathrm{X}$ \\
\hline 25 & $\begin{array}{c}\text { NARDINI } \\
\text { AGROINDUSTRIAL } \\
\text { LTDA }\end{array}$ & $\begin{array}{l}\text { Rod. GO 184, } \\
\text { km 133, Faz. } \\
\text { São Francisco }\end{array}$ & Aporé & & & & $X$ & $\mathrm{x}$ \\
\hline
\end{tabular}

Estudos Geográficos, Rio Claro, 17(1): 93-105, jan./jun. 2019 (ISSN 1678-698X) http://www.periodicos.rc.biblioteca.unesp.br/index.php/estgeo 
A territorialização do monopólio capitalista...

\begin{tabular}{|c|c|c|c|c|c|c|c|c|}
\hline 26 & $\begin{array}{c}\text { RAIZEN } \\
\text { CENTROESTE } \\
\text { AÇÚCAR E } \\
\text { ÁLCOOL LTDA }\end{array}$ & $\begin{array}{l}\text { Rod. GO 406, } \\
\text { km 25, } 6 \mathrm{~km} \text { à } \\
\text { dir., Faz. Santo } \\
\text { Antônio do Rio } \\
\text { Doce }\end{array}$ & Jataí & & & & & $x$ \\
\hline 27 & $\begin{array}{c}\text { RIO CLARO } \\
\text { AGROINDUSTRIAL } \\
\text { S/A- ODEBRECHT } \\
\text { AGROINDUSTRIAL }\end{array}$ & $\begin{array}{l}\text { Faz. Santo } \\
\text { Antônio, s/n }\end{array}$ & Caçú & & & & $x$ & $x$ \\
\hline 28 & $\begin{array}{l}\text { RIO VERDE } \\
\text { INDÚSTRIA DE } \\
\text { ÁLCOOL E } \\
\text { AÇÚCAR LTDA }\end{array}$ & $\begin{array}{c}\text { Rod. GO 174, } \\
\text { km 14, Faz. São } \\
\text { Tomaz do Rio } \\
\text { do Peixe, s/n } \\
\end{array}$ & Rio Verde & & & & $X$ & \\
\hline 29 & $\begin{array}{c}\text { SJC BIOENERGIA } \\
\text { S/A - USINA } \\
\text { CACHOEIRA } \\
\text { DOURADA }\end{array}$ & $\begin{array}{l}\text { Rod. GO 206, } \\
\text { km 25, } 1,5 \mathrm{~km} \text { à } \\
\text { esq. }\end{array}$ & $\begin{array}{l}\text { Cachoeira } \\
\text { Dourada }\end{array}$ & & & & $x$ & $x$ \\
\hline 30 & $\begin{array}{l}\text { SJC BIOENERGIA } \\
\text { S/A - USINA SÃO } \\
\text { FRANCISCO }\end{array}$ & $\begin{array}{l}\text { Rod. GO 164, } \\
\text { km 18, Faz. São } \\
\text { Francisco }\end{array}$ & Quirinópolis & & & & $x$ & $x$ \\
\hline 31 & $\begin{array}{c}\text { SMBJ- } \\
\text { AGROINDUSTRIAL } \\
\text { S/A }\end{array}$ & $\begin{array}{l}\text { Rod. BR 452, } \\
\text { km 105, Faz. } \\
\text { Nova Granada }\end{array}$ & $\begin{array}{l}\text { Bom Jesus } \\
\text { de Goiás }\end{array}$ & & & & $x$ & \\
\hline 32 & $\begin{array}{c}\text { TROPICAL } \\
\text { BIOENERGIA S/A }\end{array}$ & $\begin{array}{l}\text { Rod. GO } 410, \\
\text { km } 51\end{array}$ & Edéia & & & & $x$ & \\
\hline 33 & $\begin{array}{l}\text { URUACCU AÇÚCAR } \\
\text { E ÁLCOOL LTDA }\end{array}$ & $\begin{array}{c}\text { Estrada UR-4, } \\
\text { s/n, km 13, } \\
\text { Distrito de Água } \\
\text { Branca }\end{array}$ & Uruaçú & & & & $x$ & $x$ \\
\hline 34 & $\begin{array}{l}\text { USINA BOA VISTA } \\
\text { S/A }\end{array}$ & $\begin{array}{l}\text { Rod. GO 164, } \\
\text { km } 1\end{array}$ & Quirinópolis & & & & $x$ & $x$ \\
\hline 35 & $\begin{array}{l}\text { USINA GOIANÉSIA } \\
\text { S/A }\end{array}$ & $\begin{array}{c}\text { Rod. GO 438, } \\
\text { km 12, } \\
\text { Goianésia/ } \\
\text { Santa Rita do } \\
\text { Novo Destino }\end{array}$ & Goianésia & & & & $x$ & $x$ \\
\hline 36 & $\begin{array}{c}\text { USINA NOVA GÁLIA } \\
\text { LTDA }\end{array}$ & $\begin{array}{l}\text { Rod. GO 333, } \\
\text { sentido Rio } \\
\text { Verde/Jandaia }\end{array}$ & Paraúna & & & & $x$ & $x$ \\
\hline 37 & $\begin{array}{l}\text { USINA PANORAMA } \\
\text { S/A }\end{array}$ & $\begin{array}{c}\text { Rod. BR 452, } \\
\text { km 60, Faz. Boa } \\
\text { Sorte }\end{array}$ & Itumbiara & & & & $x$ & $x$ \\
\hline 38 & $\begin{array}{c}\text { USINA RIO VERDE } \\
\text { LTDA (DECAL - } \\
\text { DESTILARIA } \\
\text { CATANDUVA } \\
\text { LTDA.) }\end{array}$ & $\begin{array}{c}\text { Rod. GO 174, } \\
\text { km 32, Faz. } \\
\text { Alvorada }\end{array}$ & Rio Verde & & & $x$ & $x$ & $x$ \\
\hline 39 & $\begin{array}{l}\text { USINA SANTA } \\
\text { HELENA DE } \\
\text { AÇÚCAR E } \\
\text { ÁLCOOL S/A }\end{array}$ & $\begin{array}{l}\text { Rod. Mun. } \\
\text { Turvelândia, GO } \\
210, \mathrm{~km} 06\end{array}$ & $\begin{array}{l}\text { Santa } \\
\text { Helena de } \\
\text { Goiás }\end{array}$ & $x$ & $x$ & $x$ & $x$ & $x$ \\
\hline 40 & $\begin{array}{c}\text { USINA SÃO PAULO } \\
\text { ENERGIA E } \\
\text { ETANOL S/A }\end{array}$ & $\begin{array}{l}\text { Rod. GO 210, } \\
\text { km } 98\end{array}$ & Porteirão & & & & $x$ & $x$ \\
\hline 41 & $\begin{array}{l}\text { USINA SERRA DO } \\
\text { CAIAPÓ S/A }\end{array}$ & $\begin{array}{l}\text { Rod. GO 174, } \\
\text { Km 62, Faz. } \\
\text { Lago Azul }\end{array}$ & Montividiu & & & & $x$ & \\
\hline
\end{tabular}

Estudos Geográficos, Rio Claro, 17(1): 93-105, jan./jun. 2019 (ISSN 1678-698X) http://www.periodicos.rc.biblioteca.unesp.br/index.php/estgeo 
A territorialização do monopólio capitalista...

\begin{tabular}{|c|c|c|c|c|c|c|c|c|}
\hline $\mathbf{4 2}$ & $\begin{array}{c}\text { VALE DO VERDÃO } \\
\text { S/A AÇÚCAR E } \\
\text { ÁLCOOL }\end{array}$ & $\begin{array}{c}\text { Rod. GO 409, } \\
\mathrm{km} \text { 2, Faz. } \\
\text { Baessa }\end{array}$ & Turvelândia & $\mathrm{X}$ & $\mathrm{X}$ & $\mathrm{X}$ & $\mathrm{X}$ & $\mathrm{X}$ \\
\hline $\begin{array}{c}\text { VALE VERDE } \\
\text { EMPREENDIMENT } \\
\text { OS AGRÍCOLAS } \\
\text { LTDA }\end{array}$ & $\begin{array}{c}\text { Rod. GO 336, } \\
\mathrm{km} 14\end{array}$ & Itapaci & $\mathrm{X}$ & $\mathrm{X}$ & $\mathrm{X}$ & $\mathrm{X}$ & $\mathrm{X}$ \\
\hline $\begin{array}{c}\text { VALE VERDE } \\
\text { EMPREENDIMENT } \\
\text { OS AGRÍCOLAS } \\
\text { LTDA }\end{array}$ & $\begin{array}{c}\text { Rod. GO 156, } \\
\mathrm{km} 55\end{array}$ & Itapuranga & & & $\mathrm{X}$ & $\mathrm{X}$ \\
\hline
\end{tabular}

Fonte: SIFAEG, 2017.

Elaboração: Autores.

De acordo com os dados do Quadro 1, que retrata a dinâmica expansiva do setor sucroenergético de 2003 a 2013, houve um acréscimo de 27,5\% de usinas associadas ao SIFAEG, o que significou também um aumento na ocupação da terra e, consequentemente, no montante da produção.

Não obstante, em relação aos últimos dados do Quadro 1, que mostra de 2013 e 2016, houve um pequeno declínio no número de usinas associadas. Sendo que em um caso específico a usina Cosan Centroeste S/A Açúcar e Álcool passou a se chamar Raízen devido a fusão de parte dos negócios das empresas Shell e Cosan, demonstrando nitidamente o estabelecimento da territorialização do monopólio no Sudoeste goiano.

No caso específico de Goiás, o estado foi considerado pelo Plano Nacional de Agroenergia 2006-2011 uma das áreas potenciais para expansão canavieira com uso de alta tecnologia e elevada lucratividade. Essa expansão ocorreu primeiramente com a ocupação de novos espaços a partir das áreas de monoculturas tradicionais. Já em um segundo momento, observa-se a expansão sobre as áreas ocupadas pelo Cerrado e pelas culturas já instaladas fazendo surgir uma competição pela renda da terra entre graneleiros e usineiros (SILVA \& MIZIARA, 2011).

Ao analisar o avanço canavieiro sobre as áreas tradicionalmente produtoras de grãos, percebe-se que a territorialização do monopólio capitalista canavieiro vem sendo praticada sobre onde havia apenas a monopolização do território graneleiro. Reflexo desse novo momento são, por exemplo, as disputadas judiciais e o aumento da concentração fundiária nas mãos dos usineiros que arrendam e compram terras próximas às usinas e sedimentam o desenvolvimento capitalista industrial da agricultura.

Para Oliveira (2015), o desenvolvimento da agricultura capitalista, nesse caso canavieira, faz com que os capitalistas/proprietários de terras se apropriem da renda capitalista da terra e promovam uma intensificação na concentração da estrutura fundiária. Nesse processo de territorialização do capital monopolista, agricultura e indústria se unem, pois a burguesia capitalista se torna também a proprietária das terras e, consequentemente, latifundiária.

Conforme Roveiro (2014), uma das formas para conter esse avanço da concentração fundiária e aprofundamento do processo de territorialização do capital monopolista canavieiro seria o arrendamento ou a parceria como uma situação vantajosa para resguardar ao camponês o direito à renda da terra. Descrevendo o que acontece em São Paulo, a autora relata:

Estudos Geográficos, Rio Claro, 17(1): 93-105, jan./jun. 2019 (ISSN 1678-698X) http://www.periodicos.rc.biblioteca.unesp.br/index.php/estgeo 
No arrendamento a usina paga mensalidade, anuidade, ou outra avençada pelo uso da terra por período de cinco anos. Nesta modalidade a usina paga por tonelada de cana à quantidade fixa em torno de 60 toneladas por alqueire... No sistema de parceria os ganhos tendem a ser maiores para o produtor, uma vez que este está sujeito a variação do preço e produção. Uma vez que o proprietário fornecedor concorre com todos os riscos atinentes a produção. Neste sistema é estabelecida uma parceria entre usina e proprietário em que o proprietário produtor se encarrega em plantar e tratar a cana que será fornecida para a mesma usina por período de cinco anos (ROVEIRO, 2014, p. 13).

Isso não significa que o campesinato ou as pequenas e médias propriedades rurais irão desaparecer nos territórios controlados pelo monopólio capitalista canavieiro. No entanto, essa territorialização mesmo baseada nos sistemas de arrendamento ou parceria tende a gerar incertezas e dificuldades futuras para que 0 camponês volte a labutar no seu chão e para que a terra atenda sua função social.

Entre as dificuldades impostas ao retorno dos camponeses à produção na terra, uma delas é a impossibilidade de reconstruir as benfeitorias destruídas a partir do avanço da cana-de-açúcar sobre as áreas que produzem, sobretudo, alimentos básicos. Outra questão está na compra da terra do pequeno e médio produtor para o plantio da cana-de-açúcar, pois neste caso eles não conseguirão comprá-la de volta. Esse rearranjo territorial do setor agropecuário regional traz consigo um novo ciclo canavieiro que vem impor impactos socioambientais e erosão da diversidade produtiva local (CAMARGO, et al., 2008).

Conforme Oliveira (2015), quando agricultura e indústria se tornam parte de um mesmo processo, o capitalista da indústria e o proprietário de terra capitalista da agricultura se transformam em uma só empresa. Consequentemente, ao explorar o trabalhador e a terra consolida a territorialização do capital monopolista na agricultura. Esse processo varre do campo os trabalhadores e os concentram nas cidades e a reprodução ampliada do capital se desenvolve plena. Isso significa que o capitalista e agora proprietário da terra acumula ao mesmo tempo o lucro da atividade industrial da agricultura canavieira, bem como a renda da terra.

Em suma, a constatação da territorialização desse processo no Cerrado goiano expõe uma nova escala de apropriação dos territórios e integração nas redes globais extrativas a partir da produção canavieira. Isso ilustra que a territorialização do monopólio capitalista canavieiro em Goiás produz um território mundializado e desigual.

\section{CONSIDERAÇÕES FINAIS}

Diante do pesquisado fica evidente a materialização do avanço da territorialização do capital monopolista canavieiro sobre o Centro-Oeste brasileiro, com destaque para os territórios do Cerrado goiano. Sobretudo, observa-se uma disputa territorial entre a monopolização graneleira do território e a territorialização do capital monopolista canavieiro no Sudoeste de Goiás.

Enquanto essa disputa ocorre, o campesinato fica à mercê de ambos e das suas próprias condições de sobrevivência na luta pelo espaço produtivo. Não inerente ao desenvolvimento desses dois processos e a correspondente

Estudos Geográficos, Rio Claro, 17(1): 93-105, jan./jun. 2019 (ISSN 1678-698X) http://www.periodicos.rc.biblioteca.unesp.br/index.php/estgeo 
mecanização de cada um, outras preocupações referem-se à concentração fundiária e ao trabalho análogo a escravidão nas lavouras de grãos ou de cana-de-açúcar.

De um lado, grandes produtores de grãos e, também, grandes capitalistas/produtores canavieiros avançando sobre as terras e sobre a renda da terra de uma classe social camponesa que muitas vezes se vê obrigada a deixar suas propriedades e atividades em direção aos bolsões de pobreza nos territórios urbanos.

Resta saber se o Cerrado também se transformará em um "mar" de cana-deaçúcar e como a classe campesina fará para continuar sobrevivendo em meio a essa disputa em que ela acaba sendo atingida de modo direto.

\section{REFERÊNCIAS}

BRASIL. Compromisso Nacional para Aperfeiçoar as Condições de Trabalho na Cana-de-Açúcar. Disponível em 2012: $<$ http://www.secretariadegoverno.gov.br/acesso-ainformacao/perguntas/compromisso-nacional-para-aperfeicoar-as-condicoes-detrabalho-na-cana-de-acucar>. Acesso em: 10/06/2017

BRASIL. Ministério da Agricultura, Pecuária e Abastecimento. Secretaria de Produção e Agroenergia. Plano nacional de agroenergia 2006-2011. 2. ed. rev. Brasília, DF: Embrapa Informação Tecnológica, 2006.

CAMARGO, A. M. M. P. et al. Dinâmica e tendência da expansão da cana-de-açúcar sobre as demais atividades agropecuárias, Estado de São Paulo, 2001-2006. Revista Informações Econômicas, São Paulo, v.38, n.3, mar. 2008.

CASTRO, S. S. de et al. Estudo da expansão da cana-de-açúcar no Estado de Goiás: subsídios para uma avaliação do potencial de impactos ambientais. Anais... SBPC, 2008.

CHAVEIRO, E. F. Cerrado e território: conflitos socioespaciais na apropriação da Biodiversidade - os povos indígenas Karajás, Aruanã-Go. Ateliê Geográfico, Goiânia, v. 4, n. 1, 2010.

HARVEY, D. A loucura da razão capitalista: Marx e o capital no século XXI. Tradução de Artur Renzo. São Paulo: Boitempo, 2018.

INSTITUTO BRASILEIRO DE GEOGRAFIA E ESTATÍSTICA (IBGE). Área plantada: produto das lavouras temporárias - cana-de-açúcar. Disponível em: <https://sidra.ibge.gov.br/tabela/1612\#resultado>. Acesso em: 18/06/2017.

INSTITUTO BRASILEIRO DE GEOGRAFIA E ESTATÍSTICA (IBGE). Área plantada: produto das lavouras temporárias - cana-de-açúcar. Disponível em: <https://sidra.ibge.gov.br/tabela/1612\#resultado>. Acesso em: 18/06/2017.

MIZIARA, F. Expansão de fronteiras e ocupação do espaço no Cerrado: o caso de Goiás. In: Guimarães, L. D. A, SILVA, M. A. D, ANACLETO, T. C. (org.). Natureza

Estudos Geográficos, Rio Claro, 17(1): 93-105, jan./jun. 2019 (ISSN 1678-698X) http://www.periodicos.rc.biblioteca.unesp.br/index.php/estgeo 
Viva Cerrado: caracterização e conservação. Cap.VII, 1르 Edição, Goiânia: Editora UCG, 2006.

OLIVEIRA, A. U. Agricultura brasileira transformações recentes. In.: ROSS, J. L. S. (org.). Geografia do Brasil. Coleção Didática. Edusp, São Paulo, 6 ed., 2015.

2016.

A mundialização da agricultura brasileira. São Paulo: landé Editorial,

OLIVEIRA, I. J. de. A agropecuária modernizada e a sustentabilidade no cerrado: o caso do município de Jataí (GO). Boletim Goiano de Geografia, 21 (2): 47-60. jul/dez., 2001.

. Sustentabilidade de sistemas produtivos agrários em paisagens do cerrado: uma análise no município de Jataí (GO). Revista Terra Livre, Ano 20, v. 2, n. 23, p. 139-159, jul.-dez. 2004.

PETRAS, J. Brasil: o capitalismo extrativo e o grande salto para trás. Tensões Mundiais, Fortaleza, v. 10, n. 18, 19, p. 301-323, 2014.

RODRIGUES, D. M. T. Sustentabilidade do setor sucroalcooleiro na microrregião de Ceres - GO. Tese (Doutorado em Geografia), UFG, Goiânia, 2013.

SANTOS, A. M. F. T. Cana doce, trabalho amargo: o trabalho escravo na expansão territorial do agronegócio sucroenergético no estado de Goiás. Dissertação (mestrado em Geografia). Universidade Federal de Goiás, Goiânia, 2015.

SANTOS, S. O. O avanço da cana-de-açúcar sobre as áreas do agronegócio em goiás. Anais... I Seminário Nacional - Reestruturação no setor sucroenergético brasileiro: novas e velhas espacialidades. Rio de Janeiro, UFRJ, 2012.

SIFAEG - Sindicato da Indústria de Fabricação de Etanol do Estado de Goiás: Disponível em: <http://www.sifaeg.com.br/wpcontent/uploads/2017/03/RELA\%C3\%87\%C3\%830-DAS-USINAS-ASSOCIADAS-

COMPACTADA-ATUALIZADA-EM-MAR\%C3\%87O-2017-15.03.2017.pdf>. Acesso em 08/06/2017.

SILVA, A. A. \& MIZIARA, F. Avanço do setor sucroalcooleiro e expansão da fronteira agrícola em Goiás. Pesquisa Agropecuária Tropical, Goiânia, v. 41, n. 3, p. 399407, jul./set. 2011.

SILVA, W. R. Z. Logística de produção e distribuição de etanol em Goiás: desafios atuais e futuros em busca de competitividade. Anais... I Seminário Nacional Reestruturação no setor sucroenergético brasileiro: novas e velhas espacialidades. Rio de Janeiro, UFRJ, 2012.

SOARES, F. U. Estudo do potencial climático para cana-de-açúcar (sacharumssp.) no Rio Grande do Sul por meio de geoprocessamento: estudo de caso no município de Jaguari. Dissertação (mestrado em Geomática), Universidade Federal de Santa Maria, Santa Maria, 2008.

Estudos Geográficos, Rio Claro, 17(1): 93-105, jan./jun. 2019 (ISSN 1678-698X) http://www.periodicos.rc.biblioteca.unesp.br/index.php/estgeo 